\begin{tabular}{|c|l|}
\hline Title & Photoacoustic spectroscopic estimation of electron mobility in titanium(IV) oxide photocatalysts \\
\hline Author(s) & Murakami, Naoya; A be, Ryu; Prieto Mahaney, Orland Omar; Torimoto, T sukasa; Ohtani, Bunsho \\
\hline Citation & Studies in Surface Science and Catalysis, 172, 429-432 \\
\hline Issue Date & 2007 \\
\hline Doc URL & http://hdl.handle.net/2115/48670 \\
\hline Type & article (author version) \\
\hline File Information & SSSC172_429.pdf \\
\hline
\end{tabular}

Instructions for use 


\title{
Photoacoustic spectroscopic estimation of electron mobility in titanium(IV) oxide photocatalysts
}

Naoya MURAKAMI, ${ }^{1}$ Ryu ABE, ${ }^{1,2}$ Orlando Omar PRIETO MAHANEY, ${ }^{1}$ Tsukasa TORIMOTO, ${ }^{1,2}$ Bunsho OHTANI ${ }^{1,2, *}$

${ }^{1}$ Graduate School of Environmental Earth Science, Hokkaido University, Sapporo 060-0810, Japan

${ }^{2}$ Catalysis Research Center, Hokkaido University, Sapporo 001-0021, Japan

\begin{abstract}
Double-beam photoacoustic (PA) spectroscopy was employed in measurements on the decay of trivalent titanium $\left(\mathrm{Ti}^{3+}\right)$ species, in titanium(IV) oxide $\left(\mathrm{TiO}_{2}\right)$ photocatalysts, produced by trapping of photoexcited electrons. The PA signal attributed to $\mathrm{Ti}^{3+}$ rapidly decayed in the dark due to the electron transfer from $\mathrm{Ti}^{3+}$ to molecular oxygen $\left(\mathrm{O}_{2}\right)$ adsorbed on the surface. The rate of decay was evaluated for various $\mathrm{TiO}_{2}$ powders by the analysis of decay profile, and compared with the rate of photocatalytic dehydrogenation of methanol in an aqueous solution. The observed positive correlation between them suggests that both decay of $\mathrm{Ti}^{3+}$ by $\mathrm{O}_{2}$ and photocatalytic dehydrogenation of methanol are governed by the mobility of photoexcited electrons.
\end{abstract}

\section{INTRODUCTION}

Photocatalysis over semiconductors involves the absorption of light of energy larger than their band gap, generating excited electron $\left(\mathrm{e}^{-}\right)$and positive hole $\left(\mathrm{h}^{+}\right)$, and subsequent reduction and oxidation by $\mathrm{e}^{-}$and $\mathrm{h}^{+}$, respectively. Many redox reactions have been proved to proceed by photocatalysis. However, the detailed mechanism, e.g., how $\mathrm{e}^{-}$and $\mathrm{h}^{+}$, produced in the bulk of photocatalyst, move to the surface to react with adsorbed substrates, is still ambiguous. One of the most probable mechanisms of $\mathrm{e}^{-}$migration in the photocatalyst is migration in conduction band as well as hopping via electron-trapping sites and the trapped $\mathrm{e}^{-}$could be detected and quantitatively measured as trivalent titanium species $\left(\mathrm{Ti}^{3+}\right)$ [1]. Tracing of $\mathrm{Ti}^{3+}$, therefore, during the $\mathrm{TiO}_{2}$-induced photocatalytic reactions would provide the mechanistic information. The conventional methods for $\mathrm{Ti}^{3+}$ detection were, however, not suitable for in situ measurements, e.g., a photochemical method using methyl viologen requires filtration of photocatalyst particles and an ESR method does removal of $\mathrm{O}_{2}$ in the system. Photoabsorption spectroscopy would be an 
alternative method when an ultrafast pulse laser was used as excitation light source [2], but, generally speaking, such less intense photoabsorption by $\mathrm{Ti}^{3+}$ can not be detected under photoirradiation in usual photocatalytic reaction systems. Recently, we have developed a double-beam photoacoustic (PA) spectroscopic technique for in situ detection of $\mathrm{Ti}^{3+}$ and reported that PA measurement under continuous ultraviolet (UV) light irradiation enable the in situ estimation of saturation limit of molar amount of $\mathrm{Ti}^{3+}$ in $\mathrm{TiO}_{2}$ samples under the conditions similar to ordinary photocatalytic reaction systems [3]. In this paper, using $21 \mathrm{TiO}_{2}$ powders, decay of $\mathrm{Ti}^{3+}$ in the dark was investigated to elucidate the mobility of electrons which may be correlated with photocatalytic activity of each photocatalyst.

\section{EXPERIMENTAL}

\subsection{Samples}

Twenty-one $\mathrm{TiO}_{2}$ powders supplied from commercial sources (Merck and Showa Titanium ST series) and Catalysis Society of Japan as reference catalysts (JRC-TIO series) were used. Their crystal structure was determined by powder X-ray diffraction analysis and specific surface area $\left(S_{\mathrm{BET}}\right)$ was measured by nitrogen adsorption on the basis of the Brunauer-Emmett-Teller equation.

\subsection{Double-beam photoacoustic spectroscopy}

A home-made PA cell composed of an aluminum body (inside volume, ca. $1 \mathrm{~cm}^{3}$ ), a Pyrex window and two valves for gas flow was used. A powder sample was placed in the cell and the atmosphere was controlled by the flow of $\mathrm{O}_{2}$ containing methanol vapor. The measurements were conducted in the closed system at room temperature. The light source was a light-emitting diode (LED; Luxeon LXHL-NM98, emitting around $645 \mathrm{~nm}$ ) and its output intensity was modulated by a digital function generator (NF DF1905). PA signal acquired by a condenser microphone buried in the cell was amplified and monitored by a digital lock-in amplifier (NF LI5640). In addition to the modulated light, a UV-LED (Nichia NCCU033, emitting around $365 \mathrm{~nm}$ ) was also used as a simultaneous continuous irradiation $\left(0.11 \mathrm{~mW} \mathrm{~cm}^{-2}\right)$ for excitation of $\mathrm{TiO}_{2}$.

\subsection{Photocatalytic reaction}

An aqueous suspension composed of $50 \mathrm{mg}$ of $\mathrm{TiO}_{2}$ and $5 \mathrm{~cm}^{3}$ of a methanol solution (50 vol\%) containing hexachloroplatinic acid $\left(\mathrm{H}_{2} \mathrm{PtCl}_{6} \cdot 6 \mathrm{H}_{2} \mathrm{O}\right)$, the amount of which corresponds to 2-wt\% loading of platinum $(\mathrm{Pt})$, were photoirradiated under an argon atmosphere with magnetic stirring (1000 rpm). Gaseous product, hydrogen $\left(\mathrm{H}_{2}\right)$, was analyzed by gas chromatography (Shimadzu GC-8A equipped with a molecular sieve 5A column and a TCD).

\section{RESULTS AND DISCUSSION}

Figure 1 shows time-course curves of PA signal for three representative $\mathrm{TiO}_{2}$ samples. The samples were exposed to UV light for initial $30 \mathrm{~min}$ and then kept in the dark. In all case, the PA 
intensity increased by UV irradiation and then became almost saturated. The increase is attributable to accumulation of $\mathrm{Ti}^{3+}$, which has broad absorption in visible region, by capture of $\mathrm{e}^{-}$in the trapping sites as a counter part of hole consumption with methanol and simultaneous electron transfer from $\mathrm{Ti}^{3+}$ to surface-adsorbed $\mathrm{O}_{2}$ [3]. Analysis of this UV-induced rise enabled estimation of saturation limit of $\mathrm{Ti}^{3+}$ accumulation, reflecting the nature of $\mathrm{TiO}_{2}$ powders, but is not discussed here.

After UV turn-off, the PA intensity rapidly

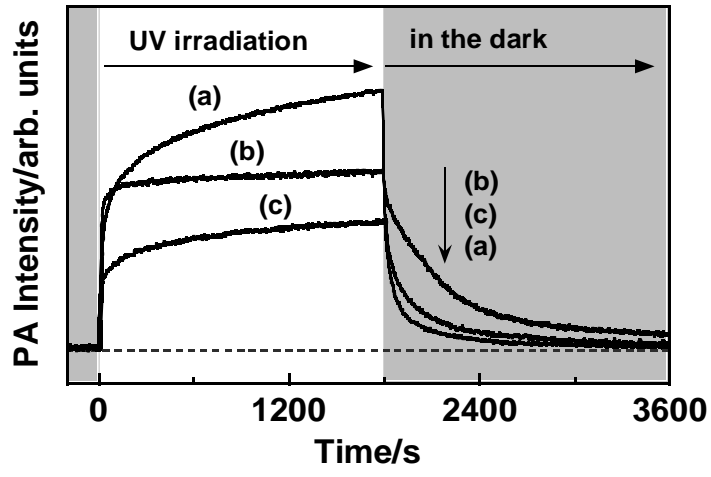

Fig. 1 Time-course curves of PA signal of (a) JRC-TIO-11, (b) JRC-TIO-1, and (c) JRC-TIO-2. decreased as Fig. 1 shows, the rate of which depended on the samples. Since the rate was much lower in the absence of $\mathrm{O}_{2}$, the decay in PA signal is attributed to the consumption of $\mathrm{Ti}^{3+}$ through the electron transfer from $\mathrm{Ti}^{3+}$ to $\mathrm{O}_{2}$ adsorbed on $\mathrm{TiO}_{2}$. Fitting these curves to a first-order (single-exponential) or second-order kinetic equation was failed suggesting the heterogeneity of location (surface or bulk) and energy level of $\mathrm{Ti}^{3+}$ and/or $\mathrm{O}_{2}$. The curves were, therefore, fitted for convenience to a set of two exponential functions $I$ (eq. (1)) and the weighted mean rate constant $\left(k_{w m}\right)$ was calculated from their components (eq. (2)).

$$
I(t)=\sum_{i=1}^{2} a_{i} \exp \left(-k_{i} t\right) \quad(1) \quad k_{w m}=\sum_{i=1}^{2} a_{i} k_{i} / \sum_{i=1}^{2} a_{i}
$$

Figure 2 shows plots of $k_{\mathrm{wm}}$ against $S_{\mathrm{BET}}$. A tendency of increasing $k_{\mathrm{wm}}$ along with the increase in $S_{\mathrm{BET}}$ was observed only for anatase-rich samples, but in overall there seems to be no appreciable correlation between them. Although at present we have no proof, the rate of $\mathrm{Ti}^{3+}$ decay is most probably governed by the mobility of $\mathrm{e}^{-}$in the $\mathrm{TiO}_{2}$ particles; the mobility might be high if $\mathrm{e}^{-}$migrates in conduction band without being trapped by the sites of energy lower than the bottom of conduction-band. The particle size may also give influence on the $\mathrm{e}^{-}$mobility; migration path length should be shorter when the size is small. Therefore, it is reasonable not to obtain appreciable correlation between $k_{\mathrm{wm}}$ and $S_{\mathrm{BET}}$ on the assumption that the $\mathrm{e}^{-}$mobility is reflected on $k_{\mathrm{wm}}$.

In Fig. 3 are plotted the photocatalytic activity, $r$, which was evaluated by $\mathrm{H}_{2}$ liberation from aqueous methanol solutions, against $k_{\mathrm{wm}}$. For $\mathrm{TiO}_{2}$ of $k_{\mathrm{wm}}<10^{-1} \mathrm{~s}^{-1}$, positive correlation between $r$ and $k_{\mathrm{wm}}$ was observed, indicating significant contribution of $\mathrm{Ti}^{3+}$ reactivity to the photocatalytic activity. It should be noted here that the Pt-deposited $\mathrm{TiO}_{2}$ was used in the photocatalytic reaction, while bare $\mathrm{TiO}_{2}$ was used in the PA measurement. In the absence of Pt, as has been observed in the PA measurement [3], $\mathrm{e}^{-}$is accumulated in the form of $\mathrm{Ti}^{3+}$, while it is well known that the Pt deposits accelerates the reaction of $\mathrm{e}^{-}$with proton or water to liberate $\mathrm{H}_{2}$. Thus, the correlation of $\mathrm{Ti}^{3+}$ reactivity reflecting $k_{\mathrm{wm}}$ with $r$ can be rationalized by assuming the intermediacy of $\mathrm{Ti}^{3+}$. Another possible interpretation is that both $r$ and $k_{\mathrm{wm}}$ are influenced, at least, by the density of trapping sites both retarding the $\mathrm{e}^{-}$migration in the dark in the absence of $\mathrm{h}^{+}$and enhancing the recombination of $\mathrm{e}^{-}$and $\mathrm{h}^{+}$by trapping. At higher $k_{w m}>10^{-1} \mathrm{~s}^{-1}, r$ was almost 
saturated. Exceptions were two $\mathrm{TiO}_{2}$ samples (JRC-TIO-3 and 6), which are pure rutile (while the others contains anatase crystallites) and exhibiting lower photocatalytic activity. Since there is a limitation of flux of photons incident on $\mathrm{TiO}_{2}$ and of rate of diffusion of substrates, methanol and/or proton, such saturation can be reasonably accepted. Even if recombination of $\mathrm{e}^{-}$ and $\mathrm{h}^{+}$is almost suppressed in $\mathrm{TiO}_{2}$ of higher $k_{\mathrm{wm}}$, the quantum efficiency can not exceed unity, since photocatalytic dehydrogenation of methanol in the absence of $\mathrm{O}_{2}$ is considered to be non radical-chain reaction.

Thus, it has been proved that the empirical rate constant of decay of photoaccumulated $\mathrm{Ti}^{3+}$ in the dark, reflecting the reactivity of $\mathrm{Ti}^{3+}$ or the $\mathrm{e}^{-}$mobility, is correlated with the rate of photocatalytic reaction by anatase-crystallites containing $\mathrm{TiO}_{2}$ samples. This suggests that both $\mathrm{e}^{-}$mobility and photocatalytic activity depends on the nature and density of electron trapping sites in $\mathrm{TiO}_{2}$.

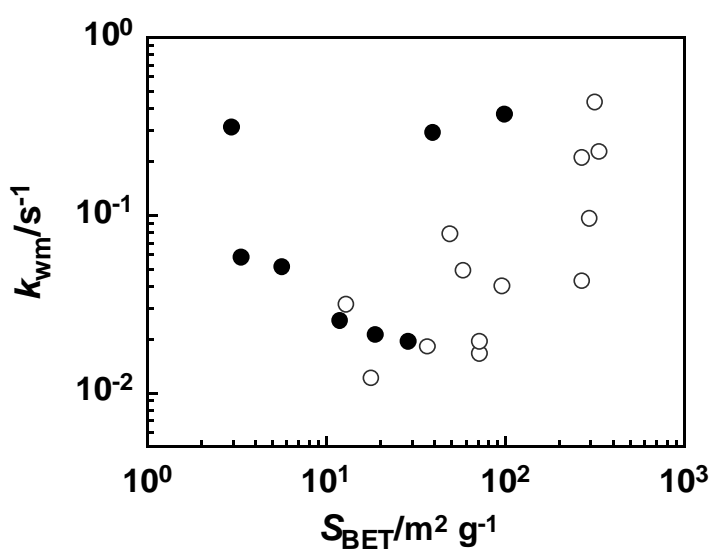

Fig. 2 Plots of $k_{\mathrm{wm}}$ against $S_{\mathrm{BET}}$. Closed and open symbols refer to mainly rutile and anatase samples, respectively.

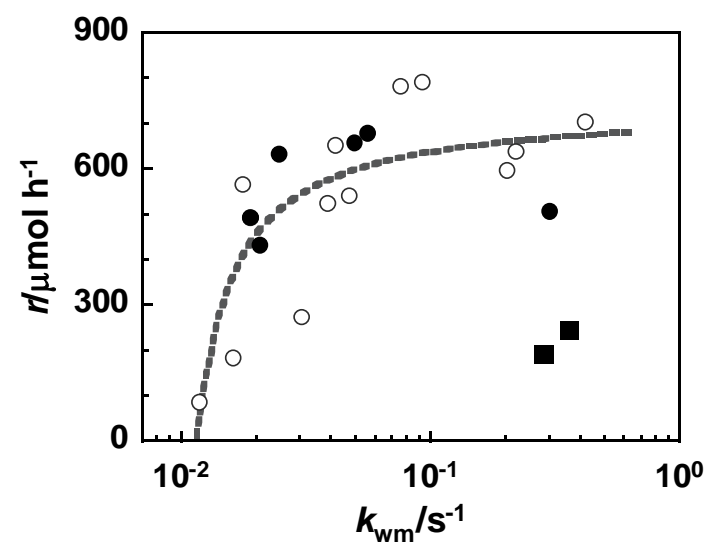

Fig. 3 Plots of $r$ against $k_{\mathrm{wm}}$. Closed and open symbols refer to mainly rutile and anatase samples, respectively. Squares show pure rutile $\mathrm{TiO}_{2}$.

\section{CONCLUSION}

Analysis of $21 \mathrm{TiO}_{2}$ samples by double-beam (intensity-modulated visible and continuous UV) PA spectroscopy revealed that the rate of decay, in the dark, of photoaccumulated $\mathrm{Ti}^{3+}$ through $^{3}$ the reaction with $\mathrm{O}_{2}$ depended on the nature of $\mathrm{TiO}_{2}$ and estimated empirical rate constant of decay was correlated with the photocatalytic activity. Thus, the present double-beam PA technique enabled to trace the change in visible-light photoabsorption arising by the UV photoirradiation of $\mathrm{TiO}_{2}$ and to obtain mechanistic information on the photocatalysis.

\section{REFERENCES}

[1] S. Ikeda, N. Sugiyama, S. Murakami, H. Kominami, Y. Kera, H. Noguchi, K. Uosaki, T. Torimoto, B. Ohtani, Phys. Chem. Chem. Phys. 5 (2003) 778 and references therein.

[2] B. Ohtani, H. Kominami, R. M. Bowman, P. Colombo Jr., H. Noguchi, K. Uosaki, Chem. Lett. 27 (1998) 579 and references therein.

[3] N. Murakami, O. O. Prieto Mahaney, T. Torimoto, B. Ohtani, Chem. Phys. Lett. 426 (2006) 204. 